\title{
Die diplomatischen Beziehungen zwischen Liechtenstein und der Tschechoslowakei bzw. Tschechien 1945 bis heute
}

\section{Diplomatic relations between Liechtenstein and Czechoslovakia and the Czech Republic from 1945 to the present day}

\section{Roland Marxer / gaschlieser16@adon.li}

Former Head of the Office for Foreign Affairs (Amt für Auswärtige Angelegenheiten) in Vaduz, President of the Kulturstiftung Liechtenstein

\begin{abstract}
This article by political scientist and long-standing high-ranking diplomat Roland Marxer provides an insight into Liechtenstein-Czech relations seen through the eyes of the Foreign Affairs Office of the Principality of Liechtenstein. For Liechtenstein as a state, for the princely family, but also for individual Liechtenstein nationals who did not belong to the princely family, a difficult situation arose after the Second World War, largely as a result of the Beneš decrees. Liechtenstein repeatedly stated to Czechoslovakia that it considered the confiscation of Liechtenstein property as assets of persons of "German nationality", which took place in 1945, to be an unacceptable violation of international law. Especially since the beginning of the 1990s, numerous initiatives have been taken at both bilateral and multilateral level in order to achieve lasting recognition of the sovereignty of Liechtenstein by Czechoslovakia, or more exactly, by its two successor states.

With the fall of the Berlin Wall and the associated changes in Eastern Europe, the European political landscape changed fundamentally, raising promising hopes for future cooperation in Europe. It must have seemed strange that three European states which were members of different European and international organizations and, as a result, were committed to cooperation that pursued the same goals, still did not have a resolution - in addition to the still

Der vorliegende Text ist eine erweiterte Fassung des Vortrags des Autors vom 19. November 2019 im Rahmen der "Liechtensteinischen Geschichtstage in der Tschechischen Republik" an der Philosophischen Fakultät der Masaryk-Universität vom 18. bis 22. November 2019 in Brünn. Der Text beruht auf der Publikation des Autors in Horčička Václav - Marxer, Roland: Liechtenstein und die tschechoslowakischen Konfiskationen von 1945 - Vom Zweiten Weltkrieg bis zur Gegenwart, Hg. von Liechtensteinisch-Tschechische Historikerkommission, Vaduz 2013, S. 141-246: Die Beziehungen Liechtensteins zur Tschechoslowakei und zu deren Nachfolgestaaten seit dem Zweiten Weltkrieg - Nachwirkungen und Entwicklungen bis heute. Dort sind auch die Quellenangaben zu finden.
\end{abstract}


unresolved issues of compensation - to mutual recognition and the establishment of diplomatic and consular relations. An agreement on the establishment of diplomatic relations and future cooperation was signed on 8 September 2009. On 7 April 2010, a Memorandum on the Establishment of the Czech-Liechtenstein Commission of Historians was signed, followed by a visit by the Czech Minister of Foreign Affairs to Vaduz.

\section{Keywords}

Principality of Liechtenstein, Czech Republic, diplomacy, international Relations, Decrees of the President of the Republic

\section{Die Beziehungen Liechtensteins zur Tschechoslowakei und zu deren Nachfolgestaaten seit dem Zweiten Weltkrieg}

Das Festhalten an sich ausschliessenden Positionen machte es über Jahrzehnte beiden Seiten unmöglich, die bilateralen Beziehungen auf eine gemeinsame Grundlage zu stellen. Erst um die Mitte des ersten Jahrzehnts des 21. Jahrhunderts zeichneten sich Lösungsmöglichkeiten ab. Nach Jahrzehnten setzte sich die Erkenntnis durch bzw. machte es eine realistische Sicht der Dinge auf der Basis eines pragmatischen Ansatzes möglich, dass sich die beiden Parteien auf konkrete Schritte, insbesondere zur Aufnahme diplomatischer Beziehungen und zur Errichtung einer bilateralen Historikerkommission, einigen konnten. Dies änderte zwar nichts an den grundsätzlich unterschiedlichen Positionen im Zusammenhang mit den Dekreten des Präsidenten der Republik (so genannten Beneš-Dekreten) und der darauf beruhenden Enteignung ohne Entschädigung des Besitzes des Fürstenhauses Liechtenstein sowie weiterer liechtensteinischer Betroffener. Es führte aber zu einer Annäherung und zur Schaffung einer Grundlage für die bilaterale Zusammenarbeit. ${ }^{1}$

Für Liechtenstein als Staat, für das Fürstenhaus, aber auch für einzelne liechtensteinische Staatsangehörige, die nicht zur Fürstlichen Familie zählten, war nach dem Zweiten Weltkrieg besonders aufgrund der Beneš-Dekrete eine schwierige Situation entstanden.

Das Haus Liechtenstein bzw. der Fürst von Liechtenstein, welcher Staatsoberhaupt des Fürstentums Liechtenstein ist, nahm und nimmt in den Beziehungen des Staates Liechtenstein mit der Tschechoslowakei bzw. heute mit der Tschechischen Republik allgemein eine wesentliche Rolle ein. In diesem Sinn wäre es vielfach kaum möglich, „staatliches“ Handeln als Handeln des Staates Liechtenstein im Interesse des Staates Liechtenstein vom Handeln des Fürstenhauses bzw. des Fürsten im Interesse des Fürstenhauses Liechtenstein zu trennen. Der Staat Liechtenstein hatte und hat nicht nur die Interessen des Fürsten als seinem Staatsangehörigen, sondern auch die Interessen

1 Marxer, Roland: Die Beziuhungen zwischen dem Fürstentum Liechtenstein und der Tschechoslowakei bzw. der Tschechischen Republik seit dem Zweiten Weltkrieg. In: Liechtensteinisch-Tschechische Historikerkommission (Hg.): Das Fürstenhaus, der Staat Liechtenstein und die Tschechoslowakei im 20. Jahrhundert. Band 4. Vaduz 2013, S. 213-236. 
anderer betroffener liechtensteinischer Staatsangehöriger zu vertreten. Angesichts dieser Ausgangslage und im Hinblick auf das Gewicht der vermögensrechtlichen Ansprüche seitens des Fürstenhauses konzentrierten sich allerdings die Bemühungen um eine Lösung der offenen Fragen auf diese Ansprüche des Fürstenhauses. 38 Personen bzw. Familien, einschliesslich des Fürstenhauses, und unter Einschluss der Enteignung des Besitzes in der heutigen Slowakischen Republik, gelten als Betroffene der Beneš-Dekrete auf liechtensteinischer Seite. ${ }^{2}$

Nach der Machtübernahme durch die Kommunistische Partei der Tschechoslowakei im Februar 1948 in Prag war es wegen der mangelnden Gesprächsbereitschaft der tschechoslowakischen Seite nicht möglich, in direkten bilateralen Verhandlungen oder im Zusammenhang mit dem schweizerisch-tschechoslowakischen Entschädigungsabkommen zu einer Lösung zu kommen. ${ }^{3}$

Liechtenstein hatte gegenüber der Tschechoslowakei ständig und wiederholt zum Ausdruck gebracht, dass es die 1945 erfolgte Konfiskation liechtensteinischen Vermögens als Vermögen von Personen „deutscher Volkszugehörigkeit“ als einen inakzeptablen Verstoss gegen das Völkerrecht ansieht.

Insbesondere seit Beginn der Neunzigerjahre des letzten Jahrhunderts wurden zahlreiche Initiativen auf bilateraler wie auch multilateraler Ebene unternommen, um die durchgehende Anerkennung der Souveränität Liechtensteins durch die Tschechoslowakei bzw. seine beiden Nachfolgestaaten zu erreichen. ${ }^{4}$

\section{Die bilateralen Bemühungen Liechtensteins um eine Lösung der offenen Fragen}

\section{Die Beziehungen Liechtensteins zur Tschechoslowakei bis 1992}

Liechtenstein bemühte sich nach dem Ersten Weltkrieg sehr darum, die Beziehungen zu Prag durch die Errichtung einer Gesandtschaft zu fördern. Prag galt als eine wichtige Aussenvertretung Liechtensteins, um den Grundbesitz des Hauses Liechtenstein in der Tschechoslowakei zu sichern und um Liechtenstein mit wichtigen Wirtschaftsgütern aus der Tschechoslowakei zu versorgen. Die Tschechoslowakei anerkannte 1918 die

2 Amt für Auswärtige Angelegenheiten (weiter AAA) Vaduz, Akten; Geiger, Peter: Bemühungen um Rückgewinnung und Rettung furstlicher Güter 1938 bis 1945. In: Liechtensteinisch-Tschechische Historikerkommission (Hrsg.), Das Furstenhaus, der Staat Liechtenstein und die Tschechoslowakei im 20. Jahrhundert, Vaduz 2013, S. 63-80; Geiger, Peter: Alle enteigneten liechtensteinischen Staatsangehörigen. Wer, was, wo? Was wurde aus dem enteigneten Besitz? In: Liechtensteinisch-Tschechische Historikerkommission (Hg.): Das Fürstenhaus, der Staat Liechtenstein und die Tschechoslowakei im 20. Jahrhundert. Band 4. Vaduz 2013, S. $185-198$.

3 Hinweise darauf im Aide-memoire der Regierung des Furstentums Liechtenstein vom 29. Oktober 1990, welches die liechtensteinische Regierung in der Erwartung verfasste, dass angesichts der damals (1990) aktuellen gesamteuropaischen Entwicklungen [...] eine zukunftsorientierte Bereinigung des Fragenkomplexes [...] von beiderseitigem Interesse ist Aide-memoire, nicht publiziert, AAA Vaduz, Akten.

4 Marxer, Roland: Liechtensteins Beziehungen zur Tschechoslowakei und zu deren Nachfolgestaaten seit 1945. Jahrbuch des Historischen Vereins fur das Fürstentum Liechtenstein 105, 2006, S. 131-152. 
liechtensteinische Souveränität nicht und lehnte 1923 die Errichtung einer liechtensteinischen Gesandtschaft in Prag und 1925 ebenfalls die Vertretung Liechtensteins durch die Schweiz ab.

Die Tschechoslowakei betrachtete den Fürsten von Liechtenstein als den Habsburgern untergeordnet. Dies machte es möglich, den Grundbesitz des Hauses Liechtenstein in die 1918 proklamierte Bodenreform einzubeziehen. „In verschiedenen Enteignungsund Veräusserungsaktionen verlor das Haus Liechtenstein in den Jahren 1921-1938 von rund 160000 Hektar Grundbesitz 91500 Hektar. Dies entsprach einem Verlust von 57,18 Prozent des Gesamtbesitzes in der Tschechoslowakei. Dabei gilt es zu beachten, dass die Entschädigungspreise nach den Durchschnittspreisen der Jahre 1913-1915 berechnet wurden." Der Entschädigungspreis habe nur einen Bruchteil des tatsächlichen Wertes des Grundbesitzes ausgemacht. ${ }^{5}$

Im Juli 1938 stimmte die Tschechoslowakei der Vertretung der liechtensteinischen Interessen durch die Schweiz für kurze Zeit zu (die Schweiz hatte Liechtenstein seit 1918 diplomatisch vertreten) und anerkannte Liechtenstein dadurch implizit als souveränen Staat. Im Oktober 1938 erfolgte der deutsche Truppeneinmarsch und im März 1939 wurde das „Protektorat Böhmen und Mähren“ geschaffen.

Im Unterschied zu Liechtenstein hatte die Schweiz 1939 die Existenz des von Deutschland geschaffenen „Protektorats Böhmen und Mähren“ und des „Slowakischen Staates“ anerkannt. Damit waren die Beziehungen der Schweiz zur Tschechoslowakischen Republik als erloschen zu betrachten. Im Februar 1945 machte die Schweiz der tschechoslowakischen Regierung im Exil in London den Vorschlag, die diplomatischen Beziehungen wieder herzustellen. Die tschechoslowakische Regierung stimmte zu. Bezüglich der Vertretung der Interessen Liechtensteins durch die Schweiz erklärte das tschechoslowakische Aussenministerium, durch die Unterbrechung der schweizerischen-tschechoslowakischen Beziehungen während des Krieges hätten sich auch die Beziehungen zu Liechtenstein gelöst. Daher erwähnte der Notenwechsel von 1945, durch welchen die diplomatischen Beziehungen zwischen der Schweiz und der Tschechoslowakei wieder hergestellt wurden, Liechtenstein nicht. Die Beziehungen zwischen der Tschechoslowakei und Liechtenstein waren somit nicht wieder hergestellt worden.

Im Jahr 1945 brach die Tschechoslowakei also die diplomatischen Beziehungen zu Liechtenstein ab und konfiszierte entschädigungslos das Vermögen aller liechtensteinischen Staatsangehörigen, das auf ihrem Staatsgebiet lag. Betroffen war vor allem das Fürstenhaus, aber auch eine Reihe liechtensteinischer Staatsangehöriger (38 Personen bzw. Familien): Liechtensteinische Staatsangehörige wurden als „Personen deutscher Nationalität“ im Sinne des Beneš-Dekrets Nr. 12 angesehen, unter Missachtung der liechtensteinischen Souveränität und Neutralität. Das gleiche Schicksal widerfuhr auch deutschsprachigen Staatsbürgern anderer Länder, z.B. der Schweiz. Die meisten dieser

5 Quaderer, Rupert: Liechtenstein und die Bodenreform in der Tschechoslowakei nach dem Ersten Weltkrieg. In: Prague Papers on the History of International Relations. Prague 2008, S. 265-290, hier 288, und dort angegebene weitere Literatur. 
Länder schlossen aber bereits unter dem kommunistischen Regime der Tschechoslowakei Entschädigungsabkommen ab. ${ }^{6}$

\section{Grundlegende Veränderungen der politischen Lage in Europa}

Mit dem Fall der Berliner Mauer, dem Zusammenbruch der ehemaligen Sowjetunion und den damit verbundenen Änderungen in Osteuropa stellte sich die europäische politische Landschaft grundlegend neu und im Hinblick auf die künftige Zusammenarbeit in Europa sehr vielversprechend dar. Es musste als eigenartig erscheinen, dass drei europäische Staaten, die verschiedenen europäischen und internationalen Organisationen angehörten und damit in einer Zusammenarbeit verbunden waren, die den gleichen Zielen verpflichtet war, unter sich - abgesehen von den dargestellten weiterhin offenen Entschädigungsfragen - noch immer nicht die gegenseitige Anerkennung sowie die Aufnahme von diplomatischen und konsularischen Beziehungen geregelt hatten. Es sollte aber doch einige Zeit dauern, bis sich eine Annäherung und Zusammenarbeit abzeichnete. Parallel zu den bilateralen Lösungsversuchen bemühte sich Liechtenstein insbesondere im Rahmen internationaler Organisationen, welchen die beiden Nachfolgestaaten der Tschechoslowakei beizutreten wünschten, um eine Positionierung seiner Interessen.

Die Beziehungen Liechtensteins zu beiden Nachfolgestaaten bewegten sich auf unterschiedlichen staatlichen und privaten Ebenen und unter Einbezug verschiedener Rollenträger mit oder ohne offizielle Zuständigkeit in die Richtung einer Normalisierung, nachdem es im Rahmen der Aktivitäten insbesondere seitens Liechtensteins im Rahmen der Erweiterung des EWR-Abkommens auf die 10 neuen EU-Länder, unter ihnen die Tschechische Republik und die Slowakische Republik, praktisch keine konkreten Fortschritte in Richtung einer völkerrechtlichen Anerkennung gegeben hatte.

\section{Die Beziehungen Liechtensteins zur Tschechischen Republik 1992-2009}

Im Oktober 1990 ersuchte Aussenminister Jiř́i Dienstbier den liechtensteinischen Regierungschef Hans Brunhart um Unterstützung der Bewerbung für den Sitz des permanenten KSZE-Sekretariats in Prag. Brunhart antwortete am 5. November 1990 dahingehend, dass Liechtenstein die Kandidatur positiv in Erwägung ziehen könne, unter der Voraussetzung, dass die liechtensteinische Regierung eine formelle Zusicherung erhalten müsse, dass die Tschechische und Slowakische Föderative Republik ebenfalls entschlossen sei, mit Liechtenstein Beziehungen auf der Basis der Grundsätze des Internationalen Rechts und des gegenseitigen Respekts zu etablieren und dass die Regierung in Prag ebenfalls bereit sei, Verhandlungen zu allen offenen Fragen in diesem Zusammenhang aufzunehmen. Dienstbier antwortete am 7. November 1990 und dankte für die „positive Stellung“ Liechtensteins bezüglich des Sitzes des Sekretariats der KSZE. Es liege ebenfalls im Interesse

6 Zu einer Ausführlichen Darstellung dieser Zeitperiode bis 1992 siehe Fussnote 1. 
seiner Regierung, die Beziehungen mit Liechtenstein auf den Prinzipien souveräner Gleichheit, Freundschaft und beiderseitig vorteilhafter Zusammenarbeit zu gestalten. Er nehme an, dass „wir sowohl unsere Beziehungen als auch Beziehungen mit allen Staaten Europas mit Perspektive eines neuen sich integrierenden Europa aufbauen werden können. Wir sind uns dessen bewusst, dass in unseren Beziehungen eine Reihe offener Fragen existiert. An ihrer Lösung möchten wir ohne Belastung von Peripetien der Vergangenheit, mit dem Gefühl gegenseitiger Achtung und Verständnis herantreten." Seine Regierung sei bereit, Verhandlungen über alle offenen Fragen aufzunehmen. ${ }^{7}$

In einem Aide-mémoire vom 29. Oktober 1990 an die Tschechische und Slowakische Regierung hielt die liechtensteinische Regierung fest, dass sie die Wiederherstellung der Demokratie in den beiden Ländern zum Anlass nehme, um die Aufmerksamkeit auf die nach wie vor aufrechten Ansprüche liechtensteinischer Staatsbürger in der Tschechischen und Slowakischen Föderativen Republik zu lenken. Sie gab dann eine Darstellung der Situation seit 1945 und schlug Verhandlungen vor.

Es kam zu drei Gesprächs- bzw. Verhandlungsrunden zwischen Liechtenstein und der Tschechoslowakei. Eine informelle Gesprächsrunde fand im Juni 1991 in Prag statt, eine erste Verhandlungsrunde im Dezember 1991 in Prag und eine zweite im Februar 1992 in Vaduz. Liechtenstein brach anschliessend die Verhandlungen ab, da sich herausstellte, dass die andere Seite auf die liechtensteinischen Vorstellungen und Forderungen nicht eingehen würde.

Im Hinblick auf den 1. Januar 1993, den Tag des Vollzugs der Teilung der Tschechischen und Slowakischen Föderativen Republik in die beiden Nachfolgestaaten, die Tschechische Republik und die Slowakische Republik, mussten sich beide Staaten bzw. in deren Interessenvertretung der vorerst noch bestehende Vorgängerstaat, die Tschechische und Slowakische Föderative Republik, um die Anerkennung durch die anderen Staaten und um die eigenständige Aufnahme in internationale Organisationen bemühen.

Im Dezember 1992, also kurz vor dem am 1. Januar 1993 geplanten Vollzug der Trennung der Tschechoslowakei in die beiden Nachfolgestaaten, teilte die Tschechoslowakische Botschaft in Bern der liechtensteinischen Seite mit, dass sich zum Datum des 31. Dezember 1992 die Tschechische und Slowakische Föderative Republik auflöse, dass die beiden Nachfolgestaaten die Tschechische Republik und die Slowakische Republik und dass diese Letzteren berechtigt seien, in ihrem eigenen Namen internationale Abkommen mit Drittstaaten abzuschliessen, und zwar schon vor der Auflösung der Tschechischen und Slowakischen Föderativen Republik am 31. Dezember 1992. In separaten Noten der tschechischen bzw. der slowakischen Regierung werde das Anliegen der Anerkennung der beiden Nachfolgestaaten ab dem 1. Januar 1993 unterbreitet. Der Eingang dieser Note vom 10. Dezember 1992 wurde von der Liechtensteinischen Botschaft in Bern am 31. Dezember 1992 lediglich bestätigt, nachdem die Tschechoslowakische Botschaft am 31. Dezember 1992 unter Hinweis auf ihre Note vom 10. Dezember 1992

7 Der Brief ist in Tschechisch abgefasst. Der zitierte Text wurde der dem Original beigefugten inoffiziellen deutschen Übersetzung etnommen. 
erneut, nun mit Datum vom 31. Dezember 1992, den Inhalt der damaligen Note des tschechoslowakischen Aussenministeriums übermittelt hatte. ${ }^{8}$

Ebenfalls am 10. Dezember 1992 - und kaum zufällig - übermittelte die Liechtensteinische Botschaft der Tschechischen und Slowakischen Botschaft in Bern den Entwurf für ein Memorandum of Understanding, ${ }^{9}$ wonach der geregelte Übergang der Staatsgewalt von der Tschechoslowakischen auf die Tschechische Republik den Anlass gebe, in Bezug auf Liechtenstein festzuhalten, dass Liechtenstein Entschädigungsforderungen gestellt habe und die Tschechische Republik ihre Bereitschaft erklären würde, hierzu Verhandlungen zu führen, um die Fragen nach völkerrechtlichen Grundsätzen und im gegenseitigen Interesse zu lösen. Sollten diese Verhandlungen zu keinem Ergebnis führen, würden bis dann noch offene Fragen einer Gerichts- oder schiedsgerichtlichen Instanz vorgelegt werden.

Mit Datum vom 18. Dezember 1992 wurde der Liechtensteinischen Botschaft in Bern eine ausführliche Dokumentation des (künftigen) tschechischen Aussenministeriums übermittelt, in welcher die Tschechische Republik ihre Rechte und Pflichten als Nachfolgestaat der ehemaligen Tschechoslowakei darlegte. Es war die Erklärung des Tschechischen Nationalen Rats an alle Parlamente und Nationen der Welt beigelegt, in welcher im Wesentlichen die aussenpolitischen Orientierungen des neuen Staates Tschechische Republik dargestellt wurden.

Analog ging das (künftige) slowakische Aussenministerium vor, indem es ebenfalls eine im Wesentlichen wortgleiche Darstellung zu den Rechten und Pflichten des künftigen Staates Slowakische Republik sowie die Proklamation des Slowakischen Nationalen Rats an alle Parlamente und Nationen der Welt übermittelte.

Mit jeweils einer eigenen Note vom 18. Dezember 1992 an die Liechtensteinische Botschaft in Bern wurde um Anerkennung der Tschechischen Republik bzw. der Slowakischen Republik und um Aufnahme diplomatischer Beziehungen auf der Ebene von Botschaften ab dem 1. Januar 1993 ersucht. ${ }^{10}$ Die liechtensteinische Seite liess sich mit einer Antwort einige Monate Zeit.

Am 31. Dezember 1992 richtete die Botschaft der Tschechischen und Slowakischen Föderativen Republik in Bern eine weitere Note an die Liechtensteinische Botschaft und ersuchte, unter Wiederholung des Inhalts ihrer Note vom 10. Dezember 1992, um Antwort Liechtensteins. $\mathrm{Zu}$ dieser Note wurde von der Liechtensteinischen Botschaft ebenfalls am 31. Dezember 1992 geantwortet, dass die zugestellten Dokumente der liechtensteinischen Regierung zugestellt worden seien. Zur gewünschten Anerkennung der beiden Staaten wurde also nicht Stellung genommen.

Am 15. März 1993 richtete die Liechtensteinische Botschaft eine Note an die Tschechische Botschaft in Bern mit folgendem Inhalt: ${ }^{11}$ „[...] Die Fürstliche Regierung, nach Kenntnisnahme der genannten Noten und der Proklamation des Parlaments der Tschechischen

8 AAA Vaduz, Akten.

9 Analoge Noten gingen, wie bekannt wurde, auch an alle anderen Staaten.

10 AAA Vaduz, Akten.

11 Übersetzung des Autors aus der franzosischen Originalfassung; AAA Vaduz, Akten. 
Republik vom 17. Dezember 1992, ist bereit, auf der Basis der Gegenseitigkeit die Tschechische Republik, einen souveränen und unabhängigen Staat, anzuerkennen, und schlägt im Hinblick auf die Aufnahme diplomatischer Beziehungen vor, in Verhandlungen über alle damit zusammenhängenden und noch offenen Fragen zwischen den beiden Staaten zu treten. Unter diesen offenen Fragen sei das Eigentum von liechtensteinischen Staatsangehörigen zu erwähnen, welches auf dem Gebiet der Tschechischen Republik von der tschechoslowakischen Regierung enteignet und ohne Entschädigung im Jahr 1945 und danach verstaatlicht worden ist. " Die Regierung erwarte in naher Zukunft eine entsprechend mandatierte tschechische Delegation in Vaduz.

Die Tschechische Botschaft erklärte mit Note vom 14. April 1993 das Einverständnis des tschechischen Aussenministeriums mit den von Liechtenstein gemachten Vorschlägen.

Die informellen bilateralen Gespräche konnten somit am 22. und 23. April 1993 in Vaduz stattfinden. ${ }^{12}$ Wie erwähnt, hatte eine erste formelle Verhandlungsrunde am 17. Dezember 1991 in Prag stattgefunden, eine zweite am 17.-18. Februar 1992 in Vaduz, also noch vor der Aufteilung der Tschechoslowakei in ihre Nachfolgestaaten. Beide Verhandlungsrunden wie auch die Gespräche vom April 1993 brachten keine Annäherung in den grundsätzlich unterschiedlichen Positionen. Die tschechische Delegation war nicht in der Lage, auf Entschädigungsverhandlungen einzutreten. Die Möglichkeit der Ebene und Form der diplomatischen Vertretung wurde angesprochen, aber nicht definitiv behandelt.

Damit waren Fortschritte erneut blockiert. Trotzdem fand am 17. August 1993 ein inoffizieller Besuch einer Delegation des tschechischen Parlaments in Vaduz statt, unter der Leitung von Parlamentsvizepräsident Pavel Tollner.

Anlässlich des Forums Alpbach trafen sich im August 1994 Fürst Hans-Adam II. und Präsident Václav Havel. Der Fürst erklärte vor den Medien, dass es ihm nicht um die Rückgabe der Besitzungen in der Tschechischen Republik gehe, die der Fürstlichen Familie und liechtensteinischen Bürgern gehörten, sondern es gehe vor allem darum, dass die liechtensteinischen Bürger von tschechischer Seite als Bürger eines souveränen Staates anerkannt werden, wie dies alle anderen Staaten auch tun. ${ }^{13}$

Es gab ausserdem in den Jahren 1994 und 1995 unterschiedliche Begegnungen auf politischer bzw. Regierungsebene bei verschiedenen Gelegenheiten, die aber alle nicht zu konkreten Ergebnissen zu den offenen Fragen führten.

Anschliessend fanden auf bilateraler Ebene, soweit ersichtlich, keine offiziellen (persönlichen) Kontakte mehr statt.

Liechtenstein hatte sich durchgehend auf den Standpunkt gestellt, dass die Entschädigungsfragen einer Lösung zugeführt werden müssten, wenn die formelle Anerkennung der beiden Nachfolgestaaten durch Liechtenstein und die Aufnahme diplomatischer Beziehungen zwischen Liechtenstein erfolgen sollten. Konkrete Fortschritte konnten also aus liechtensteinischer Sicht nur im Rahmen und Umfang eines Gesamtpakets an Lösungen erzielt werden. Die beiden Nachfolgestaaten der Tschechoslowakei hielten ihrerseits an der Position fest, es seien zuerst die diplomatischen Beziehungen aufzu-

12 Verhandlungsleiter auf liechtensteinischer Seite war Botschafter Prinz Nikolaus von Liechtenstein, auf tschechischer Seite Milan Kováč, Stellvertretender Direktor im tschechischen Aussenministerium.

13 Liechtensteiner Vaterland vom 18. Oktober 1994. 
nehmen, anschliessend könnten alle (anderen) offenen Fragen in den Beziehungen der drei Staaten zueinander geklärt werden.

Die liechtensteinische Position beinhaltete immer auch das Argument, dass die Verantwortung gegenüber Liechtenstein von der früheren Tschechoslowakei an die beiden Nachfolgestaaten übergegangen sei, was von diesen beiden Staaten - soweit ersichtlich-grundsätzlich nicht bestritten wurde. Dementsprechend hatte die liechtensteinische Regierung die identischen Fragen und Probleme ursprünglich mit der Tschechoslowakei und anschliessend mit den beiden Nachfolgestaaten - und mit diesen dann auf separatem Weg und mit unterschiedlichen bilateralen Kontakten - behandelt. Eine Annäherung der Standpunkte ist bisher im Wesentlichen ausgeblieben. ${ }^{14}$

Die Anerkennungsfrage bzw. das Fehlen von diplomatischen Beziehungen verhinderte im Übrigen nicht, dass es unter anderem einen Briefwechsel betreffend die Anerkennung tschechischer Nachlass-Urteile durch Liechtenstein gab. Weder die tschechische Seite, welche die Anfrage stellte, noch Liechtenstein, das sie dahingehend beantwortete, dass die Anerkennung nur auf der Basis eines Staatsvertrags möglich wäre, nahmen darauf Bezug. ${ }^{15}$

Auch ohne die Etablierung diplomatischer Beziehungen erfolgte der diplomatische Verkehr über die jeweiligen Botschaften in Bern in Routineangelegenheiten, wie etwa der Bekanntgabe von Ferienabwesenheiten des Botschaftspersonals, der Mitteilung von militärischen Informationen gemäss Wiener Dokument über vertrauensbildende Massnahmen oder andere Informationen, offenbar ohne Probleme. So dankte z.B. der liechtensteinische Botschafter in Bern, Prinz Nikolaus von Liechtenstein, für das am 25. Januar 1994 an ihn gerichtete Schreiben des als tschechischer Botschafter bei der Eidgenossenschaft akkreditierten Botschafters Richard Belcredi, in welchem dieses Faktum den in Bern akkreditierten Botschaften mitgeteilt wurde, am 28. Januar 1994.

Als weitere Beispiele eines pragmatischen bzw. eines als diplomatisch wohl als unproblematisch erachteten Umgangs hochrangiger Persönlichkeiten beider Länder miteinander mögen die Glückwünsche von Präsident Václav Havel an Fürst Hans-Adam II. zum Neujahr 2003, von Aussenminister Cyril Svoboda an Aussenminister Ernst Walch zu Jahresbeginn 2003 und 2004, von Fürst Hans-Adam II. und Fürstin Marie an Präsident Václav Klaus zu Weihnachten 2004 und Neujahr 2005, von Präsident Václav Klaus an Fürst Hans-Adam II. zu seinem 60. Geburtstag (am 14. Februar 2005), von Senatspräsident Přemysl Sobotka an Landtagspräsident Klaus Wanger zum Neujahr 2006, von Aussenminister Cyril Svoboda an Aussenministerin Rita Kieber-Beck zum Neujahr 2006 und von Erbprinz Alois im Namen des Fürsten an Präsident Václav Klaus (als Antwort auf die Glückwünsche des Letzteren) für das Jahr 2006 gelten.

Auch im Bereich der humanitären Hilfe seitens Liechtensteins können Beispiele angeführt werden: So leistete Liechtenstein 1991 Beiträge zur Beseitigung der

14 Die Gesprache und Kontakte mit den beiden Nachfolgestaaten erfolgten getrennt und auch zeitlich nicht durchgehend parallel.

15 Korrespondenz zwischen der Tschechischen und der Liechtensteinischen Botschaft in Bern vom 3. November 2003 und 6. Februar 2004; Liechtensteinisches Landesarchiv Vaduz (weiter LILA) 143/4835, Akte Botschaft Bern 9202.3. 
Überschwemmungsfolgen für ein Sanierungsprogramm und 2002 für die Instandsetzung von Kulturgütern im Agneskloster in Prag.

Am 11. Dezember 1997 wurde von Aussenministerin Andrea Willi dem tschechischen Botschafter in Bern, Richard Belcredi, in Anwesenheit des Direktors der Schule, Zdeněk Boten, eine Spende von CHF 50000 der liechtensteinischen Regierung an die Kosten der Beseitigung der Folgen der Überschwemmungen in der Tschechischen Republik für Sanierungsmassnahmen im Gymnasium von Uherské Hradistě überreicht. ${ }^{16}$

Am 16. Januar 2003 erfolgte die Überreichung eines Schecks von 340000 CHF durch Botschafterin Maria-Pia Kothbauer an den tschechischen Kulturminister Pavel Dostál für die Instandsetzung von bedeutenden Kulturgütern im Agneskloster in Prag und in der Schlossbibliothek in Terezín (Theresienstadt) sowie für die Wiederherstellung von Brückenstegen in einer kleinen tschechischen Gemeinde in der Folge des Hochwassers vom Sommer 2002 in Tschechien.

Allerdings gab es auch andere Beispiele. So erklärte Fürstin Marie in einem Brief vom 24. März 2003 an den slowakischen Präsidenten Rudolf Schuster, sie könne die Einladung zu einem Mittagessen in Bratislava nicht annehmen. Da die offenen Fragen zwischen Liechtenstein und der Tschechischen Republik bzw. der Slowakischen Republik immer noch nicht geklärt seien, könne ein offizieller Besuch aus innen- und aussenpolitischen Gründen nicht stattfinden. Sie würde sich aber freuen, ihn einmal zu einem privaten Besuch im Palais in Wien empfangen zu können. ${ }^{17}$

Anfragen betreffend die Errichtung von Honorarkonsulaten Liechtensteins in der Tschechoslowakei bzw. in der Tschechischen Republik wurden von Liechtenstein über die Jahre hinweg immer negativ beantwortet. In einer ersten Phase galt die Begründung, dass Liechtenstein keine Honorarkonsulate in Drittstaaten errichte, was der tatsächlichen Praxis entsprach. Dies geschah etwa in einem Schreiben des Amtes für Auswärtige Angelegenheiten in Vaduz vom 8. Oktober 1990 an einen Interessenten aus Prag. Später erfolgte die Ablehnung auch mit dem Argument im Hintergrund, dass keine diplomatischen Beziehungen zwischen den beiden Ländern bestanden.

Andererseits war Liechtenstein, als die Schweiz und die Tschechische und Slowakische Föderative Republik im Jahr 1990 die Visumspflicht gegenseitig aufhoben, gemäss Artikel 9 der Vereinbarung in Form eines Notenwechsels vom 31. Juli 1990, welcher am 15. August 1990 in Kraft trat, mit einbezogen. Das Abkommen wurde mit Notenaustausch vom 31. Juli 2003 - 9. März 2004 ersetzt. Die Anwendung auf Liechtenstein ist nunmehr in Artikel 7 geregelt. Dies ergab sich vor allem aus dem Umstand, dass die Schweiz und Liechtenstein aufgrund der fremdenpolizeilichen Zusammenarbeit ein gemeinsames Visum-Regime hatten und haben. Heute sind beide Staaten, wie auch die Slowakische Republik, Mitglieder im Schengen-System.

16 Liechtensteiner Vaterland, 13. 12. 1997.

17 AAA Vaduz, Akten. 


\section{Deutsch-Tschechische Erklärung vom 21. Januar 1997}

Die Unterzeichnung der Deutsch-Tschechischen Erklärung vom 21. Januar 1997 nahm die liechtensteinische Regierung zum Anlass, um sowohl Deutschland als auch die Tschechische Republik auf ihre Rechtspositionen bezüglich der Beneš-Dekrete hinzuweisen. ${ }^{18}$

\section{Die multilateralen Bemühungen Liechtensteins von 1993-2005}

Für die beiden Nachfolgestaaten der Tschechoslowakei hatte ihre Selbständigkeit zur Folge, dass sie (neu) um Aufnahme in diejenigen internationalen Gremien ansuchen mussten, in welchen die Tschechoslowakei vor ihrer Auflösung bereits Mitglied gewesen war.

Parallel zum bilateralen Vorgehen war die liechtensteinische Regierung darauf bedacht, in internationalen Organisationen, schon vor der Teilung der Tschechischen und Slowakischen Föderativen Republik und vor allem auch nachher, in geeigneter Weise auf die offenen Fragen in den Beziehungen Liechtensteins zur Tschechischen und zur Slowakischen Republik hinzuweisen. Die jeweiligen Verfahren zur Aufnahme der beiden Staaten in internationale Institutionen boten daher Liechtenstein die Gelegenheit, auf die offenen Fragen in den Beziehungen zu diesen beiden Staaten hinzuweisen.

Dies ist geschehen bei der Aufnahme der Tschechischen Republik und der Slowakischen Republik in die Konferenz über Sicherheit und Zusammenarbeit in Europa (KSZE), in den Europarat, in das Freihandelsabkommen der EFTA-Staaten mit der Tschechoslowakei bzw. ihren Nachfolgestaaten, in die UNO und in das Europäische Patentübereinkommen.

$\mathrm{Zu}$ einer echten Auseinandersetzung unter den betroffenen Staaten kam es anlässlich der Aufnahme der Tschechischen Republik und der Slowakischen Republik in den Europäischen Wirtschaftsraum.

Der Beitritt der beiden Staaten zur EU erfolgte am 1. Mai 2004. Das Abkommen des Europäischen Wirtschaftsraums war im Jahr 1992 zwischen den damaligen EG-Staaten und den damaligen EFTA-Staaten abgeschlossen worden. Da alle EU-Staaten Vertragsparteien des Abkommens über den Europäischen Wirtschaftsraum (EWR) sind bzw. mit ihrem EU-Beitritt werden müssen, war mit der EU-Erweiterung von 2004 auch eine Anpassung des EWR-Abkommens notwendig, das der Zustimmung aller Vertragsparteien, also auch Liechtensteins, bedurfte.

In einem Aide-mémoire vom 4. April 2003 zuhanden aller künftigen Vertragsparteien begrüsste die Regierung die anstehende EWR-Erweiterung und die fortschreitende Integration in Europa. Sie machte aber gleichzeitig auch auf die offenen Fragen in den Beziehungen zwischen Liechtenstein und der Tschechischen Republik und der Slowakischen Republik aufmerksam. Die Regierung stellte nicht die aus Sicht der betroffenen Staaten behauptete Rechtmässigkeit der Beneš-Dekrete in Frage, sondern behandelte 
die offenen Fragen unter dem für Liechtenstein wesentlichen Aspekt der Anerkennung der liechtensteinischen Souveränität. Die Regierung stellte dar, dass das EWR-Abkommen ein Vertrag unter internationalem Recht ist und daher die Vertragsparteien sich gegenseitig als souveräne Staaten anerkennen müssen. Im Weiteren wurde auf die bisher geführten Verhandlungen zu den offenen Fragen eingegangen und es wurden Vorschläge zum weiteren Vorgehen gemacht. Die Regierung erklärte dabei, dass sie sich bewusst sei, dass die Frage der Behandlung von Eigentum nicht in kurzer Frist bereinigt werden kann. Die Regierung verlangte aber von den beiden Staaten, wie dies deren Vorgängerstaat, die Tschechoslowakei, im Jahr 1938 tat, dass die beiden Staaten Liechtenstein vorbehaltlos als souveränen Staat anerkennen und ihre Bereitschaft erklären, zu den offenen Fragen bezüglich des Eigentums im Rahmen einer friedlichen Streitbeilegung eine Lösung zu erreichen. Vor diesem Hintergrund hatte Liechtenstein diesbezüglich den beiden Staaten eine Note zukommen lassen und die Vertragsparteien des Erweiterungsabkommens um Unterstützung der Anliegen Liechtensteins ersucht. Ausserdem hatte der liechtensteinische Aussenminister Ernst Walch am 4. April 2003 in einem Schreiben an seinen Amtskollegen Cyril Svoboda darauf hingewiesen, dass die Tschechische Republik zu jenen 10 Staaten gehöre, mit welchen ein EWR-Erweiterungsabkommen abzuschliessen sei, und er gab inhaltlich in etwa wieder, was auch im Aidemémoire mit gleichem Datum enthalten war.

Es folgten dann in den Jahren 2003 und 2004 verschiedene Vorstösse von liechtensteinischer Seite, um in bilateralen Erklärungen der betroffenen Parteien zur Anerkennungsfrage Stellung zu nehmen. Es kann hier nicht auf all die Nuancen dieser Diskussionen eingegangen werden.

Der liechtensteinische Aussenminister Ernst Walch bemühte sich, in Begleitung des isländischen Aussenministers Halldór Ásgrímsson in Prag in Verhandlungen mit dem tschechischen Aussenminister Cyril Svoboda kurz vor dem offiziellen Unterzeichnungsdatum um eine Lösung, die schliesslich aber nicht zustande kam. So wurden dem EWRErweiterungsabkommen Erklärungen der drei Vertragsparteien beigefügt, die zu den offenen Fragen keine Einigung beinhalten konnten.

Die Regierung sah sich aber aufgrund der Ausgangslage vorerst nicht in der Lage, die Unterzeichnung des Abkommens am 13. bzw. 14. Oktober 2003 vorzunehmen. Darüber informierte sie alle künftigen Vertragsparteien am 13. Oktober 2003. Island und Norwegen schlossen sich am 14. Oktober dieser Haltung solidarisch an und beide Staaten bemühten sich anschliessend, in Absprache mit Liechtenstein, über Verhandlungen einen Kompromiss zu erreichen.

Schliesslich beschloss die Regierung in Absprache mit Island und Norwegen, im Interesse des Weiterbestands des EWR und seiner Erweiterung - beides wurde von der Regierung nie in Frage gestellt - das Abkommen am 11. November 2003 in Vaduz zusammen mit Island und Norwegen zu unterzeichnen. Italien, das den EU-Vorsitz innehatte, unterzeichnete es zusammen mit der Kommission am gleichen Tag. Trotz dieser Verschiebungen betreffend den Ort und das Datum der Unterzeichnung des EWR-Erweiterungsabkommens ist in diesem der Unterzeichnungsort Luxemburg und das Datum vom 14. Oktober 2003 enthalten. 
Anlässlich der Ratifikation dieses Erweiterungsabkommens gab Liechtenstein eine weitere Erklärung ab, die nicht nur das Verständnis beinhaltete, dass sich die Vertragsparteien verpflichten, „sich um die Beilegung zwischen ihnen bestehender, bislang ungelöster Streitigkeiten auf friedlichem Wege auf der Grundlage des Völkerrechts" zu bemühen, sondern auch, dass „mit der Ratifikation dieses Übereinkommens das Bestehen des Fürstentums Liechtensteins als seit langem bestehender souveräner Staat auch für die in Artikel 1 dieses Übereinkommens genannten <neuen Vertragsparteien> ausser Zweifel steht. "19

Die Hinterlegung der liechtensteinischen Ratifikationsurkunde erfolgte am 28. April 2004, das Abkommen wurde ab 1. Mai 2004 vorläufig angewendet und trat für Liechtenstein am 6. Dezember 2005 definitiv in Kraft. Diese lange Frist ergab sich daraus, dass andere Vertragsparteien die Ratifikationsurkunde erst längere Zeit nach Liechtenstein hinterlegten. Liechtenstein hatte also in keiner Weise das Inkrafttreten des Abkommens verzögert.

Auch im Zusammenhang mit dem von der EU angestrebten Abkommen der EU über die Zinsbesteuerung bestätigte die Regierung die in ihrer Sicht konsequente Haltung in einer Erklärung anlässlich der Unterzeichnung des Abkommens am 7. Dezember 2004 mit folgendem Wortlaut: ${ }^{20}$

„Das Fürstentum Liechtenstein legt diesem Abkommen, das dem gemeinsamen Interesse der weiteren Entwicklung der privilegierten Beziehung zwischen der Gemeinschaft und dem Fürstentum Liechtenstein dienen soll, das gemeinsame Verständnis zugrunde, dass Ziel und Zweck dieses Abkommens, wie sie sich insbesondere in der Präambel und in Artikel 1 manifestieren, zum Ausdruck bringen, dass die Gemeinschaft und ihre Mitgliedstaaten das Fürstentum Liechtenstein als einen seit langem bestehenden souveränen Staat respektieren, mit dem alle bestehenden wie auch eventuell künftigen Konflikte mit den Mitteln der friedlichen Streitbeilegung auf der Grundlage des Völkerrechts gelöst werden.

Dieses gemeinsame Verständnis bildet für das Fürstentum Liechtenstein die Grundlage für die vertrauensvolle Zusammenarbeit, wie sie die Durchführung des Abkommens generell und insbesondere von Artikel 10 erfordert."

Diese Erklärung war wieder in der Ratifikationsurkunde Liechtensteins enthalten. Auch diese Erklärung blieb von Tschechien und von der Slowakei gegenüber Liechtenstein unwidersprochen. Wenn auch die Souveränität Liechtensteins 1945 nicht ausdrücklich genannt wird, so umfasst der Ausdruck „seit langem bestehender souveräner Staat“ auch diesen Zeitpunkt zumindest implizit.

19 AAA Vaduz, Akten.

20 Bericht und Antrag der Regierung Nr. 3/2005, S. 18; das «Abkommen zwischen dem Fürstentum Liechtenstein und der Europäischen Gemeinschaft über Regelungen, die denen der Richtlinie 2003/48/EG des Rates uber die Besteuerung von Zinsertragen gleichwertig sind (Zinsbesteuerungsabkommen) $\gg$ trat am 1. Juli 2005 in Kraft, Liechtensteinisches Landesgesetzblatt (weiter LGBl.) 2005, Nr. 111. 


\section{Initiativen von Fürst Hans-Adam II. bzw. von Liechtenstein}

Im Zusammenhang mit dem sog. „Kalkofen-Bild“, das aus Brünn im Jahr 1991 zu einer Ausstellung nach Köln gelangt war und welches zu dem 1945 dem Fürstenhaus enteigneten Vermögen gehörte, erhob der Fürst Klage vor den deutschen Gerichten. ${ }^{21}$ Er hatte jedoch keinen Erfolg. Darauf richtete sich der Fürst mit einer Individualbeschwerde an den Europäischen Gerichtshof für Menschenrechte in Strassburg. ${ }^{22}$ Auch dieses Vorgehen war nicht von Erfolg gekrönt. Schliesslich erhob Liechtenstein Klage gegen Deutschland vor dem Internationalen Gerichtshof (IGH) in Den Haag. Insbesondere das Verfahren vor dem IGH war von tschechischer Seite mit grossem Interesse und wohl auch mit einiger Sorge verfolgt worden, da sich bei einem anderen Ausgang der Entscheidung überaus bedeutende Folgen hätten ergeben können. ${ }^{23}$

Zusammenfassend lässt sich feststellen, dass die jahrzehntelangen Bemühungen um eine Annäherung erfolglos geblieben waren, wenn man den Erfolg nur an konkreten Ergebnissen messen wollte. Es bedurfte eines politischen Reifungsprozesses auf beiden Seiten, um einen Schritt weiter zu kommen. Insbesondere die diplomatischen Bemühungen im Zusammenhang mit dem EWR-Erweiterungsabkommen dürften dazu beigetragen haben, dass dieser Reifungsprozess schliesslich Früchte tragen konnte. Hierzu war gewiss eine pragmatische Haltung auf Seiten Liechtensteins bzw. des liechtensteinischen Fürstenhauses Voraussetzung, wie sie in der im Vergleich zu früher offeneren Haltung Liechtensteins zu Tage trat - die Frage der Anerkennung und der Aufnahme diplomatischer Beziehungen wurde dabei wie dargestellt vom früheren Junktim mit der Enteignungs- und Entschädigungsfrage abgekoppelt. Dies bot die Chance für einen Neubeginn.

\section{Ein Neubeginn}

Sowohl der frühere Fürst Franz Josef II. wie auch Fürst Hans-Adam II. hatten mehrere Versuche unternommen, um auf dem Gerichtsweg ihre Forderungen gegenüber der Tschechoslowakei bzw. gegenüber der Tschechischen Republik durchzusetzen. Diesen Bemühungen war kein Erfolg beschieden. Die innerstaatlichen Verfahren vor tschechischen Gerichten waren ohne Perspektive, der Weg über internationale Gerichte war erschöpft. Die intensiven Bemühungen von Seiten Liechtensteins im Zusammenhang mit der Unterzeichnung des EWR-Erweiterungsabkommens hatten keine konkreten Ergebnisse im Sinne einer Annäherung gebracht. Sollte ein weiterer Stillstand in den

21 Pieter van Laer: „Szene aus einem romischen Kalkofen“. Siehe „Obraz velká vápenka a majetkoprávní nároky Lichtenštejnů vůči ČR.“ In: Město Valtice, online: http://www.valtice.cz/Default.aspx?id=90. Genommen am 10. 10. 2020.

22 Application no. 42527/98, Prince Hans Adam against Germany; Judgment of 12 July 2001.

23 Certain Property (Liechtenstein v. Germany), Entscheidung des IGH vom 10. Februar 2005, www.icj-cij. org; Pressemitteilung der Regierung vom 10. Februar 2005. Interview von Roland Marxer mit Botschafter Jiři Šitler vom 4. September 2012. 
Beziehungen vermieden werden, galt es neue Wege zu finden. Dies ergab sich insbesondere auch vor dem (aussen)politischen Hintergrund, dass nicht nur Drittstaaten, welche Kenntnis von der Situation hatten, diese für zusehend „anormal“ hielten, sondern auch die direkt betroffenen Parteien, wenn auch mit nicht identischen Argumenten. Für Liechtenstein stellte sich generell für seine Aussenpolitik unter anderem die Frage, auf welchem Weg es neue Verbündete finden konnte. Die Tschechische Republik sah sich vor der Situation, dass jüngere tschechische Historiker sich vermehrt mit der tschechoslowakischen bzw. tschechischen Geschichte des 20. Jahrhunderts befassten und durchaus auch kritische Fragen zu den Beneš-Dekreten stellten und behandelten.

Der Erfolg des sich abspielenden Szenarios stand vor allem im Zeichen des Vertrauens massgeblicher Persönlichkeiten zueinander und des klaren politischen Willens, eine Lösung aus der blockierten Situation zu finden. Es konnte nicht darum gehen, die grundsätzlich unterschiedlichen Positionen im Zusammenhang mit den Beneš-Dekreten in Übereinstimmung zu bringen, sondern, trotz dieser unterschiedlichen Positionen, den Weg für die Aufnahme diplomatischer Beziehungen und für die bilaterale Zusammenarbeit einzuschlagen. Den Schlüssel hierzu bildete die Einsetzung einer gemeinsamen Historikerkommission, welche einerseits die Beziehungen des Fürstenhauses Liechtenstein zur Tschechoslowakei bzw. zur Tschechischen Republik und andererseits die Beziehungen des Staates Liechtenstein zur Tschechoslowakei bzw. zur Tschechischen Republik umfassend aufarbeiten sollte.

$\mathrm{Zu}$ den eigentlichen Protagonisten gehörten seitens des Fürstenhauses Erbprinz Alois in Vertretung des Fürsten und seitens der Tschechischen Republik Aussenminister Schwarzenberg, während auf Beamtenebene Botschafter Rudolf Jindrák und Botschafterin Maria-Pia Kothbauer besonders hervorzuheben sind. Den Letzteren oblag die Vorbereitung und Ausformulierung der Texte, die schliesslich die bilateralen Vereinbarungen ermöglichten, welche am 8. September 2009 zur Unterzeichnung der Vereinbarungen über die Aufnahme diplomatischer Beziehungen und über die künftige Zusammenarbeit und zum Besuch der liechtensteinischen Aussenministerin in Prag führten.

Am 7. April 2010 erfolgte die Unterzeichnung der Vereinbarung betreffend eine Historikerkommission und der Besuch des tschechischen Aussenministers in Vaduz.

Die gegenseitige Akkreditierung von Botschaftern erfolgte für den nicht-residierenden tschechischen Botschafter (Boris Lazar) mit Sitz in Bern am 13. Januar und für die nicht-residierende liechtensteinische Botschafterin (Maria-Pia Kothbauer) mit Sitz in Wien am 11. April 2011.24

Analog zum Vorgehen mit der Tschechischen Republik konnte auch mit der Slowakischen Republik ein Einvernehmen erzielt werden. Am 21. Dezember 2009, also rund drei Monate nach dem Aussenministertreffen in Prag, wurde von Aussenministerin Aurelia Frick und Aussenminister Miroslav Lajčák in Bratislava das „Memorandum über die Aufnahme diplomatischer Beziehungen zwischen dem Fürstentum Liechtenstein und der Slowakischen Republik“ unterzeichnet. Es gab also keine gesonderte „Erklärung“ über die Aufnahme von diplomatischen Beziehungen. Im Unterschied zur Lösung zwischen

24 Mitteilung des Presse- und Informationsamtes vom 11. April 2011. 
Liechtenstein und der Tschechischen Republik, bei welcher eine Erklärung über die Aufnahme diplomatischer Beziehungen sowie je ein Memorandum of Understanding über die künftige Zusammenarbeit bzw. die Errichtung einer gemeinsamen Historikerkommission unterzeichnet wurde, wurden zwischen Liechtenstein und der Slowakischen Republik nur ein Memorandum of Understanding verhandelt, welches aus der Sicht beider Staaten alle notwendigen Festlegungen enthält.

Bezüglich der Errichtung diplomatischer Vertretungen sprach sich der slowakische Minister dafür aus, den slowakischen Botschafter in Bern in Liechtenstein zu akkreditieren. Von liechtensteinischer Seite wurde dies akzeptiert mit dem Hinweis, dass es dem üblichen Vertretungsmodell ohne Reziprozität entspreche und Liechtenstein im Gegenzug keinen Botschafter in Bratislava akkreditieren werde. Als erster slowakischer Botschafter in Liechtenstein wurde am 25. August 2010 Ján Foltín mit Sitz in Bern akkreditiert. Sein offizieller diplomatischer Kontakt mit Vaduz erfolgt über das liechtensteinische Aussenministerium bzw. über das Amt für Auswärtige Angelegenheiten.

Die Schweiz ist weiterhin für die konsularischen Beziehungen Liechtensteins in der Slowakischen Republik, in Routineangelegenheiten seit dem September 2011 durch die Konsularabteilung der Schweizer Botschaft in Wien, zuständig.

Zwischen Liechtenstein und der Slowakei wurde auch ein regelmässiger Politischer Dialog auf hoher Ebene etabliert. Das erste entsprechende Treffen auf hoher Beamtenebene fand auf Einladung von Botschafter Roland Marxer, Leiter des Amtes für Auswärtige Angelegenheiten, am 30. März 2011 in Vaduz statt. Die slowakische Delegation stand unter der Leitung von František Ružička, Generaldirektor in der Sektion für Europäische Angelegenheiten im Slowakischen Aussenministerium.

\section{Entwicklungen seit der Aufnahme diplomatischer Beziehungen zwischen Liechtenstein und der Tschechischen Republik im Jahre 2009}

Die Pflege der Beziehungen zwischen Liechtenstein und Tschechien wurde seit Aufnahme der diplomatischen Beziehungen im Herbst 2009 konsequent weitergeführt. 2010 konzentrierte sich die Zusammenarbeit insbesondere auf die Etablierung der Historikerkommission sowie auf die Weiterführung der Zusammenarbeit im kulturellen und wirtschaftlichen Bereich. 2011 und 2012 erfolgte eine weitere Vertiefung der Beziehungen. Mittlerweile fanden zahlreiche Begegnungen auf politischer Ebene und auf Beamtenebene statt. Der Politische Dialog Liechtenstein - Tschechische Republik fand erstmals am 25. Mai 2012 in Vaduz statt. Die Zusammenarbeit auf dem Gebiet der Justiz und insbesondere der Kultur konnte intensiviert werden. Ein wichtiges Element stellt auch die Gruft Vranov u Brna (Wranau) dar, wo Fürst Hans-Adam die Restaurierungsarbeiten finanziell unterstützte. Im Bereich Bildung fanden und finden diverse Kontakte auf der Ebene der Schulbehörden und vor allem auch der Universitäten statt. Seit mehreren Jahren bereits findet ein wissenschaftlicher Austausch zwischen dem Liechtenstein-Institut in Bendern/Liechtenstein und tschechischen Historikern statt. Ein reger Austausch 
findet auch zwischen den Archiven in Liechtenstein und Tschechien statt.

Die Zusammenarbeit auf multilateraler Ebene fokussiert sich auf den Europäischen Wirtschaftsraum, insbesondere im Zusammenhang mit dem EU-Finanzierungsmechanismus.

Im Bericht zu den Aussenpolitischen Prioritäten Liechtensteins von 2012 wurde Folgendes festgehalten: ${ }^{25}$

„Das Fürstentum Liechtenstein und die Tschechische Republik nahmen am 8. September 2009 diplomatische Beziehungen auf. Mit diesem Schritt konnten beide Länder ihre bilateralen Beziehungen nach einem über 70-jährigen Unterbruch, welcher durch die entschädigungslosen Enteignungen liechtensteinischen Eigentums durch die damalige Tschechoslowakei bedingt war, wieder aufnehmen. [...] Mit der Aufnahme der diplomatischen Beziehungen begann der Prozess der Normalisierung der bilateralen Beziehungen. Die Tschechische Republik gehört wie Liechtenstein dem Europäischen Wirtschaftsraum an. Beide Staaten teilen gemeinsame Werte und sind enge Handelspartner. Die über 700-jährige Geschichte des Hauses Liechtenstein in Böhmen und Mähren verbindet das Fürstentum Liechtenstein und die Tschechische Republik zudem auf einzigartige Weise. Aus der zunächst schwierigen Ausgangslage ergeben sich somit für Liechtenstein ganz besondere Möglichkeiten der Zusammenarbeit mit einem mitteleuropäischen Land, das voll eingebettet in die Europäische Union - immer auch sehr bewusst seinen eigenständigen Weg geht $[\ldots]^{*}$

\section{Zusammenfassung}

Für Liechtenstein als Staat, für das Fürstenhaus, aber auch für einzelne liechtensteinische Staatsangehörige, die nicht zur Fürstlichen Familie zählten, war nach dem Zweiten Weltkrieg besonders aufgrund der Beneš-Dekrete eine schwierige Situation entstanden. Liechtenstein hatte gegenüber der Tschechoslowakei ständig und wiederholt zum Ausdruck gebracht, dass es die 1945 erfolgte Konfiskation liechtensteinischen Vermögens als Vermögen von Personen „deutscher Volkszugehörigkeit“ als einen inakzeptablen Verstoss gegen das Völkerrecht ansieht.

Insbesondere seit Beginn der Neunzigerjahre des letzten Jahrhunderts wurden zahlreiche Initiativen auf bilateraler wie auch multilateraler Ebene unternommen, um die durchgehende Anerkennung der Souveränität Liechtensteins durch die Tschechoslowakei bzw. seine beiden Nachfolgestaaten zu erreichen.

Mit dem Fall der Berliner Mauer und den damit verbundenen Änderungen in Osteuropa stellte sich die europäische politische Landschaft grundlegend neu und im Hinblick auf die künftige Zusammenarbeit in Europa sehr vielversprechend dar. Es musste als eigenartig erscheinen, dass drei europäische Staaten, die verschiedenen europäischen und internationalen Organisationen angehörten und damit in einer Zusammenarbeit verbunden waren, die den gleichen Zielen verpflichtet war, unter sich - abgesehen von den dargestellten weiterhin offenen Entschädigungsfragen - noch immer nicht die

25 Prioritaten der Liechtensteinischen Aussenpolitik, Bericht des Ressorts Ausseres, Vaduz 2012, S. 32f. 
gegenseitige Anerkennung sowie die Aufnahme von diplomatischen und konsularischen Beziehungen geregelt hatten.

Die jahrzehntelangen Bemühungen um eine Annäherung waren erfolglos geblieben waren, wenn man den Erfolg nur an konkreten Ergebnissen messen wollte. Es bedurfte eines politischen Reifungsprozesses auf beiden Seiten, um einen Schritt weiter zu kommen. Die Frage der Anerkennung und der Aufnahme diplomatischer Beziehungen wurde schliesslich vom früheren Junktim mit der Enteignungs- und Entschädigungsfrage abgekoppelt. Dies bot die Chance für einen Neubeginn.

Der Erfolg des sich abspielenden Szenarios stand vor allem im Zeichen des Vertrauens massgeblicher Persönlichkeiten zueinander und des klaren politischen Willens, eine Lösung zur blockierten Situation zu finden. Es konnte nicht darum gehen, die grundsätzlich unterschiedlichen Positionen im Zusammenhang mit den Beneš-Dekreten in Übereinstimmung zu bringen, sondern, trotz dieser unterschiedlichen Positionen, den Weg für die Aufnahme diplomatischer Beziehungen und für die bilaterale Zusammenarbeit einzuschlagen. Den Schlüssel hierzu bildete die Einsetzung einer gemeinsamen Historikerkommission, welche einerseits die Beziehungen des Fürstenhauses Liechtenstein zur Tschechoslowakei bzw. zur Tschechischen Republik und andererseits die Beziehungen des Staates Liechtenstein zur Tschechoslowakei bzw. zur Tschechischen Republik umfassend aufarbeiten sollte. ${ }^{26}$

\section{Resumé}

\section{Diplomatické vztahy mezi Lichtenštejnskem a Československem, resp. Českou republikou od roku 1945 dodnes}

Článek politologa a dlouholetého vysoce postaveného diplomata Rolanda Marxera podává pohled na lichtenštejnsko-české vztahy viděný očima Úřadu pro zahraniční záležitosti Lichtenštejnského knížectví.

Pro Lichtenštejnsko jako stát, pro knížecí rod, ale i pro jednotlivé lichtenštejnské státní příslušníky, kteří nepatřili ke knížecí rodině, vznikla po druhé světové válce zejména kvưli Benešovým dekretům těžká situace.

Lichtenštejnsko dávalo Československu neustále a opakovaně na vědomí, že pokládá konfiskace lichtenštejnského majetku jako majetku osob „německé národní př́íslušnosti“, k nimž došlo v roce 1945, za neakceptovatelné porušení mezinárodního práva.

Zejména od počátku devadesátých let 20. století byly podniknuty četné iniciativy na bilaterální i multilaterální úrovni za účelem dosažení trvalého uznání suverenity Lichtenštejnska ze strany Československa, resp. obou jeho nástupnických států.

S pádem Berlínské zdi a s tím spojenými změnami ve východní Evropě se zásadně změnila ev-

$26 \mathrm{Zu}$ tschechisch-liechtensteinischen Beziehungen siehe auch Geiger, Peter - Knoz, Tomáš - Fučíková, Eliška - Horák, Ondřej - Horel, Catherine - Kräftner, Johann - Županič, Jan - Winkelbauer, Thomas: Liechtensteinisch-tschechische Beziehungen in Geschichte und Gegenwart: Synthesebericht der Liechtensteinisch-Tschechischen Historikerkommission. Vaduz 2014. 
ropská politická situace, což vyvolalo mnohoslibné naděje na budoucí spolupráci v Evropě. Muselo se jevit jako zvláštní, že tři evropské státy, které byly členy různých evropských a mezinárodních organizací, a v důsledku toho zavázány ke spolupráci, která byla vedena stejnými cíli, neměly mezi sebou - odhlédneme-li od zmíněných i nadále nedořešených otázek odškodnění - stále ještě upraveno vzájemné uznání a navázání diplomatických a konzulárních styků.

V dubnu 1993 se uskutečnily neformální bilaterální rozhovory. První kolo formálních jednání se konalo v roce 1991 v Praze, druhé v roce 1992 ve Vaduzu. Obě kola jednání ani rozhovory v dubnu 1993 nepřinesly sblížení zásadně rozdílných pozic.

Podepsání Česko-německé deklarace 21. ledna 1997 pojala lichtenštejnská vláda jako příležitost, aby jak Německo, tak i Českou republiku upozornila na svůj právní postoj k Benešovým dekretům.

Samostatnost obou nástupnických států Československa měla za následek, že musely znovu žádat o přijetí do mezinárodních organizací, jejichž členem bylo před svým zánikem Československo.

Souběžně s bilaterálními jednáními kladla lichtenštejnská vláda už před rozdělením Československa a především pak po něm důraz na to, aby vhodným způsobem upozorňovala na otevřené otázky ve vztazích Lichtenštejnska a České a Slovenské republiky na poli mezinárodních organizací. Př́slušné procesy při přijímání obou nástupnických států do mezinárodních institucí poskytly Lichtenštejnsku př́ležitost poukázat na otevřené otázky ve vztazích s těmito dvěma státy.

Ke skutečnému sporu mezi dotčenými státy došlo při přijímání České republiky a Slovenské republiky do Evropského hospodářského prostoru.

Souhrnně lze konstatovat, že kdybychom snahy o sblížení, které trvaly několik desetiletí, měli posuzovat jen podle konkrétních výsledků, zůstaly by bez úspěchu. Na obou stranách byl potřeba určitý proces politického zrání, aby se pokročilo o krok dále. Zejména diplomatické úsilí v souvislosti s dohodou o rozšíření EHP zřejmě přispělo k tomu, že toto zrání nakonec přineslo ovoce. Předpokladem k tomu byl určitě pragmatický postoj na straně Lichtenštejnska, resp. lichtenštejnského knížecího rodu ve srovnání s dřívějším otevřenějším postojem - jak zmíněno, otázka uznání a navázání diplomatických styků přestala být oproti dřívějšímu období neodlučitelně vázána na otázku vyvlastnění a odškodnění. To poskytlo šanci na nový začátek.

Úspěch scénáře, který se následně odehrál, se nesl především ve znamení vzájemné důvěry rozhodujících osobností a jasné politické vůle najít východisko ze zablokované situace. Nemohlo jít o to sladit zásadně rozdílné pozice v souvislosti s Benešovými dekrety, ale najít navzdory těmto rozdílným pozicím cestu k navázání diplomatických styků a zahájení bilaterální spolupráce. Klíčem k tomu bylo ustavení společné komise historiků, která měla se širokým záběrem zkoumat jednak vztahy mezi knižecím rodem Lichtenštejnů a Československem, resp. Českou republikou, a jednak vztahy mezi státem Lichtenštejnsko a Československem, resp. Českou republikou.

Dne 8. září 2009 byla podepsána dohoda o navázání diplomatických styků a budoucí spolupráci. Dne 7. dubna 2010 následovalo podepsání Memoranda o ustavení Česko-lichtenštejnské komise historiků a návštěva českého ministra zahraničních věcí ve Vaduzu.

Analogicky jako tomu bylo s Českou republikou, se podařilo dosáhnout shody i se Slovenskou republikou. 21. prosince 2009, tedy přibližně tři měsíce po schůzce českého ministra a lichtenštejnské ministryně zahraničí v Praze, podepsala ministryně zahraničí Aurelia Frick a slovenský ministr zahraničí Miroslav Lajčák v Bratislavě „Memorandum o navázání diplomatických styků mezi Lichtenštejnským knížectvím a Slovenskou republikou“. 
